\section{RMD Open}

Rheumatic \&

Musculoskeletal Diseases

\title{
Lifestyle factors may modify the effect of disease activity on radiographic progression in patients with ankylosing spondylitis: a longitudinal analysis
}

\author{
Sofia Ramiro, ${ }^{1,2}$ Robert Landewé, ${ }^{1,3}$ Astrid van Tubergen, ${ }^{4,5}$ Annelies Boonen, ${ }^{4,5}$ \\ Carmen Stolwijk, ${ }^{4,5}$ Maxime Dougados, ${ }^{6,7}$ Filip van den Bosch, ${ }^{8}$ \\ Désirée van der Heijde ${ }^{9}$
}

To cite: Ramiro S, Landewé $R$, van Tubergen $A$, et al. Lifestyle factors may modify the effect of disease activity on radiographic progression in patients with ankylosing spondylitis: a longitudinal analysis. $R M D$ Open 2015;1:e000153. doi:10.1136/rmdopen-2015000153

- Prepublication history for this paper is available online. To view these files please visit the journal online (http://dx.doi.org/10.1136/ rmdopen-2015-000153).

Received 16 July 2015 Revised 18 August 2015 Accepted 22 August 2015

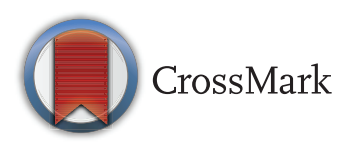

For numbered affiliations see end of article.

Correspondence to Dr Sofia Ramiro; sofiaramiro@gmail.com

\section{ABSTRACT}

Objectives: To investigate the complex relationship between inflammation, mechanical stress and radiographic progression in patients with ankylosing spondylitis (AS), using job type as a proxy for continuous mechanical stress.

Methods: Patients from the Outcome in Ankylosing Spondylitis International Study were followed up for 12 years, with 2-yearly assessments. Two readers independently scored the X-rays according to the modified Stoke Ankylosing Spondylitis Spine Score (mSASSS). Disease activity was assessed by the AS Disease Activity Score $C$ reactive protein (ASDASCRP). The relationship between ASDAS and spinal radiographic progression was investigated with longitudinal analysis, with job type at baseline (physically demanding ('blue-collar') versus sedentary ('white-collar') labour) as a potential factor influencing this relationship. The effects of smoking status and socioeconomic factors were also investigated.

Results: In total, 184 patients were included in the analyses $(70 \%$ males, $83 \%$ human leucocyte antigen-B27 positive, $39 \%$ smokers, $48 \%$ blue-collar workers $(65 / 136$ patients in whom data on job type were available)). The relationship between disease activity and radiographic progression was significantly and independently modified by job type: In 'blue-collar' workers versus 'white-collar' workers, every additional unit of ASDAS resulted in an increase of 1.2 versus 0.2 mSASSS-units/2-years ( $p=0.014$ for the difference between blue-collar and white-collar workers). In smokers versus non-smokers, every additional unit of ASDAS resulted in an increase of 1.9 versus 0.4 mSASSSunits/2-years.

Conclusions: Physically demanding jobs may amplify the potentiating effects of inflammation on bone formation in AS. Smoking and socioeconomic factors most likely confound this relationship and may have separate effects on bone formation.

\section{Key messages}

What is already known about this subject?

- Higher disease activity leads to radiographic progression in ankylosing spondylitis (AS).

What does this study add?

- Physically demanding jobs may amplify the potentiating effects of inflammation on bone formation in AS.

- Smoking and socioeconomic factors confound this relationship and may have separate effects on bone formation.

How might this impact on clinical practice?

- More research is needed, specifically into the type of physical activity that may be deleterious and lead to radiographic progression, before these findings can have an impact on clinical practice.

\section{INTRODUCTION}

In ankylosing spondylitis (AS), radiographic progression of the spine is faster in males, in human leucocyte antigen (HLA)-B27-positive patients, in patients with active disease and in those who already have signs of damage. ${ }^{1-5}$ We have recently shown that disease activity is longitudinally associated with radiographic progression. ${ }^{5}$ This effect is amplified in males and in patients with shorter symptom duration. ${ }^{5}$ Part of syndesmophyte formation was 'constitutive': even in the absence of disease activity patients had some progression. ${ }^{5}$ A clear and overarching biological explanation of syndesmophyte formation in AS is still lacking, but, in analogy with osteophyte formation in osteoarthritis, ${ }^{6}$ there may be a contributory role for mechanical stress. 
Mice that were tail suspended, so that mechanical loading on paws was low, showed less bone formation than those kept in regular cages, ${ }^{7}$ which is a proof of concept for the proposition that mechanical strain drives new bone formation in spondyloarthritis (SpA). In addition, sparse data have suggested that jobs with physically demanding activities are associated with more radiographic damage. ${ }^{8}$

A detailed analysis of how mechanical stress and inflammation may interact in explaining radiographic progression has never been conducted, because the idea of lifetime mechanical stress is difficult to quantify and because the contribution of inflammation to syndesmophyte formation has long been obscure. However, it is rational to postulate that radiographic progression is the result of a combination of different factors (among which are disease activity and mechanical stress), rather than the sole consequence of one factor.

We have recently established the potential contribution of inflammation to radiographic progression in the Outcome in Ankylosing Spondylitis International Study (OASIS cohort), using the AS Disease Activity Score (ASDAS) as a proxy for inflammation; we have also formulated the idea of 'constitutive progression' (independent of inflammation). ${ }^{5}$ We think the OASIS cohort may be the appropriate template to study the interplay between inflammation and mechanical stress. In the light of the problem to quantify 'long-term mechanical stress', and in the absence of appropriate direct data, we have chosen 'job type' (physically demanding vs sedentary) as a proxy for 'lifetime mechanical stress' on the spine.

We have also taken potential confounders into consideration: smoking was shown to be predictive of radiographic progression in patients with axial $\mathrm{SpA} .{ }^{3}$ It is easy to hypothesise that smoking is associated with 'job type', but smoking may also have an independent effect on radiographic progression. Likewise, socioeconomic factors such as personal income may interfere because they may be associated with 'job type'. ${ }^{9-11}$

We have performed a detailed aggregated analysis focusing on the effects of 'job type', smoking and factors reflecting socioeconomic status on radiographic progression in AS.

\section{METHODS}

\section{Study population}

Data from OASIS were used. OASIS is a prevalence cohort starting (1996) with 217 consecutive patients with AS from the Netherlands, Belgium and France. ${ }^{12}$ Clinical and radiographic (cervical and lumbar spine) data were collected every 2 years during a period of 12 years. Patients were included in the present study if they had at least two subsequent radiographs and data on disease activity as well as on occupational activities and/or smoking status and/or socioeconomic factors (educational level, personal income and/or family income) were available. All patients gave informed consent and the ethics committee from all participating hospitals approved the study.

\section{Radiographic damage}

Radiographs were scored using the modified Stoke Ankylosing Spondylitis Spine Score (mSASSS), which ranges from 0 (no damage) to 72 (maximal damage). ${ }^{13}$ Two well-trained readers (SR and CS) independently scored all available radiographs per patient, blinded to demographic and clinical data, but with known chronology. ${ }^{14}$ Mean reader scores were used. Details of the reading methodology have been reported elsewhere. ${ }^{1}$

\section{Disease activity and occupational activity, smoking status and socioeconomic factors}

The disease activity measure of choice was ASDAS, ${ }^{15}$ which best reflects the association between disease activity and radiographic progression. ${ }^{5}$

Patient-reported information about occupation (collected at baseline by an open question) was used as a proxy for unmeasured lifetime mechanical stress on the spine. 'Job type' was determined by consensus, without knowledge of disease activity and/or radiographic damage. Two job types were distinguished: 'blue-collar' and 'white-collar' jobs, which are common circumscriptions for manual jobs (that imply more physical labour) and more sedentary jobs (that imply less physical activities), respectively. ${ }^{16}{ }^{17}$ Examples of 'blue-collar workers' are craftworkers, labourers and transportation operatives. Examples of 'white-collar workers' are managers, administrative workers, teachers and engineers. The analyses were performed under the assumptions that (1) 'job type' at baseline reflects 'lifetime job type'; and (2) 'blue-collar jobs' are associated with more mechanical stress on the spine than 'white-collar jobs'.

Smokers versus non-smokers were distinguished based on baseline smoking status. If baseline information was not available, patients were retrospectively questioned in order to minimise missing data.

Socioeconomic factors were collected at baseline and included (1) educational level (collected in seven categories and dichotomised into higher professional and university education vs any other level of education; (2) baseline gross monthly personal income and family income (collected in 10 categories and dichotomised at $€ 1588$ (personal income) and $€ 3176$ (family income), respectively. These amounts demarcate income classes $1-4$ versus $5-10$.

\section{Statistical analysis}

The template for the analysis of the effects of 'job type' on radiographic progression was based on the longitudinal analysis that has been presented in detail elsewhere. ${ }^{5}$ In brief, mSASSS over time $(\mathrm{t})\left(\mathrm{mSASSS}_{\mathrm{t}}\right)$ was longitudinally modelled using generalised estimating equations (GEE), assuming an exchangeable working correlation structure for mSASSS in order to adjust for within-patient correlation. ${ }^{5}$ 
In the first model (referred to as the DIRECT model since we investigated the direct effect of 'job type' on radiographic progression), 'job type' was introduced by testing the interaction of 'job type' and 'time' on mSASSS $_{\mathrm{t}}$. Using similar methodology, we investigated the effects of smoking and the socioeconomic factors, separately and in combination with 'job type'.

Second, the potential of the 'job type' to modify the established relationship between disease activity and mSASSS $_{\mathrm{t}}{ }^{5}$ (referred to as the INDIRECT model, as we investigated the effect of 'job type' on the relationship between ASDAS and radiographic progression) was analysed in our autoregressive model with 2-year time lags as proposed previously. ${ }^{5}$ Briefly, a '2-year time-lag' here means that disease activity at the start of a 2-year interval $\left(\right.$ ASDAS $\left._{\mathrm{t}}\right)$ is associated with radiographic progression during the subsequent 2-year interval (or: mSASSS $_{t}$ was modelled by ASDAS $_{\mathrm{t}-1}$ and by mSASSS $_{\mathrm{t}-1}$ (autoregressive component)). 'Job type' was tested in interaction with the longitudinal variable 'ASDAS'. Similar INDIRECT models were run for the lifestyle factors smoking and socioeconomic factors. In the presence of relevant interactions (arbitrarily defined as interactions with $\mathrm{p}<0.1$ ), analyses were repeated in subgroups.

Figure 1 represents graphically the DIRECT and INDIRECT models that were conducted to investigate the effects that the 'exposure' (eg, occupational activity) could have on radiographic damage. Note that the consequences of both models are fundamentally different.

Goodness-of-fit statistics (Quasi-likelihood under the Independence model Criterion (QIC)), with lower QICs reflecting better data fit, were used to select the best models. Owing to missing information regarding occupational activity, smoking status and the different socioeconomic factors, analyses were first conducted in all patients with each of the variables available. Next, sensitivity analysis in patients with complete data (missing family income was allowed) was conducted. None of the other measured variables in OASIS appeared to be confounders of the relationship between disease activity and radiographic progression as shown in previous analyses $^{5}$ and were omitted from this analysis.

Analyses were performed using Stata SE V.12 (Statacorp, College Station, Texas, USA).

\section{RESULTS}

In total, 184 patients (70\% males, 83\% HLA-B27 positive) were included in the analyses (table 1). These patients had similar baseline characteristics as those included in the entire OASIS cohort, and patients who were followed up until year 12 were similar to those initially included in the study, ${ }^{5}$ just as those included in the sensitivity analysis ( $\mathrm{N}=85$; table 2). Of the 136 patients with baseline occupational activity available, 65 (48\%) were assigned a 'blue-collar' job.

Expectedly, 'blue-collar' workers $(86 \%)$ were more often of male gender than 'white-collar' workers $(63 \%)$, and men $(82 \%)$ were more often smokers than women $(63 \%)$. Importantly, 'blue-collar' workers had a higher level of ASDAS than 'white-collar' workers, as well as a higher mSASSS at baseline (table 1). 'White-collar' workers had a higher level of education and a higher personal income. At baseline, none of the patients were treated with tumour necrosis factor inhibitors and $68 \%$ of the patients were treated with non-steroidal anti-inflammatory drugs. More details on this study population can be found in our previous publication. ${ }^{5}$ Information of job type over time was available for 92 patients, of whom only 1 patient had a change in job type (from blue to white collar), and even this was a temporary change; the others remained stable in their job type throughout the entire follow-up.

\section{The DIRECT model: effects of 'job type' on radiographic progression}

Radiographic progression was slightly but significantly higher in 'blue-collar' than in 'white-collar' workers: 2.18 mSASSS-units/ 2 years (95\% CI 1.52 to 2.84 ) versus

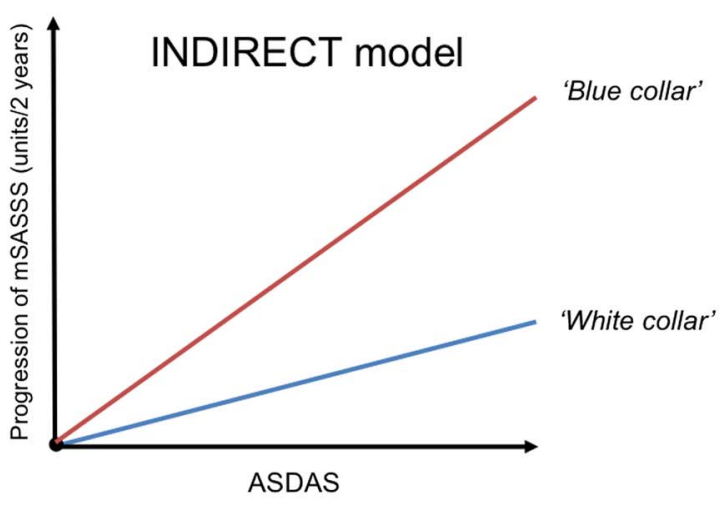

Figure 1 Different scenarios that explain the effect that an external factor (here occupational activity-blue collar vs white collar -used as an example) could hypothetically have on radiographic damage. (A) Occupational activity as a predictor of the course of mSASSS over time, modifying this evolution over time; (B) occupational activity as a factor modifying the relationship between ASDAS and mSASSS. Graphs represent hypothetical scenarios and not real data. mSASSS, modified Stoke Ankylosing Spondylitis Spine Score; ASDAS, Ankylosing Spondylitis Disease Activity Score. 
Table 1 Baseline demographic, clinical and radiographic characteristics of all patients stratified by baseline smoking status and by baseline occupational activity

\begin{tabular}{|c|c|c|c|c|c|}
\hline Assessment & $\begin{array}{l}\mathrm{N}=184 \\
\text { mean }(\mathrm{SD}) \\
\text { or } \mathrm{n}(\%)\end{array}$ & $\begin{array}{l}\text { Blue-collar jobs* } \\
N=65 \text { mean (SD) } \\
\text { or } n(\%)\end{array}$ & $\begin{array}{l}\text { White-collar jobs* } \\
\mathrm{N}=71 \text { mean } \\
(\mathrm{SD}) \text { or } n(\%)\end{array}$ & $\begin{array}{l}\text { Smokerst } \\
N=49 \text { mean } \\
(S D) \text { or } n(\%)\end{array}$ & $\begin{array}{l}\text { Non-smokers } \\
\mathrm{N}=78 \\
\text { mean (SD) } \\
\text { or } \mathrm{n}(\%)\end{array}$ \\
\hline Age (years) & $43(12)$ & $40(12)$ & $41(11)$ & $38(11)$ & $42(12)$ \\
\hline Male gender (\%) & $129(70)$ & $56(86)$ & $45(63)$ & $40(82)$ & $49(63)$ \\
\hline HLA-B27 positive (\%) & 149 (83) & $50(79)$ & $61(88)$ & $43(88)$ & $61(78)$ \\
\hline Symptoms duration (years) & $20(12)$ & $17(10)$ & $18(9)$ & $16(10)$ & $20(11)$ \\
\hline Disease duration (years) & $11(9)$ & $9(8)$ & $11(8)$ & $8(6)$ & $11(9)$ \\
\hline ASDAS-CRP & $2.6(1.0)$ & $2.9(1.0)$ & $2.4(0.9)$ & $2.8(1.0)$ & $2.6(1.1)$ \\
\hline BASDAI (0-10) & $3.4(2.0)$ & $3.7(2.0)$ & $2.9(1.9)$ & $3.4(1.9)$ & $3.2(2.2)$ \\
\hline CRP (mg/L) & $17.4(23.3)$ & $18.2(21.6)$ & $15.7(23.0)$ & $18.9(23.0)$ & $17.9(25.9)$ \\
\hline Elevated CRP (\%)‡ & $85(48)$ & $30(48)$ & $34(50)$ & $25(53)$ & $37(49)$ \\
\hline mSASSS (0-72) & $10.8(15.2)$ & $11.0(14.7)$ & $6.4(8.6)$ & $9.9(15.9)$ & $9.3(13.7)$ \\
\hline mSASSS >0 (\%) & $140(81)$ & $50(81)$ & $50(78)$ & $31(72)$ & $60(80)$ \\
\hline NSAIDs (\%) & $125(68)$ & $46(71)$ & $50(70)$ & $36(73)$ & $54(69)$ \\
\hline University education (\%) & $14(8)$ & $1(2)$ & $12(17)$ & $1(2)$ & $9(12)$ \\
\hline $\begin{array}{l}\text { Monthly personal income } \\
\geq € 1588(\%)\end{array}$ & $56(35)$ & $17(28)$ & $32(52)$ & $16(38)$ & $23(34)$ \\
\hline Monthly family income $\geq € 3176$ (\%) & $21(19)$ & $4(9)$ & $14(35)$ & $6(21)$ & $10(21)$ \\
\hline Smoker (\%) & $49(39)$ & $23(51)$ & $17(33)$ & - & - \\
\hline Blue-collar worker (\%) & $65(48)$ & - & - & $23(58)$ & $22(39)$ \\
\hline
\end{tabular}

*Baseline occupational activity was missing for 48 patients 6 retired, 25 work-disabled, 4 housewives, 2 not working for own choice, 3 students, 1 unemployed and 7 with missing baseline occupational activity missing).

†Baseline smoking status was missing for 57 patients.

¥The cut-off was $10 \mathrm{mg} / \mathrm{L}$ for the Dutch patients and $5 \mathrm{mg} / \mathrm{L}$ for the Belgian and French patients.

ASDAS-CRP, Ankylosing Spondylitis Disease Activity Score (C reactive protein); BASDAI, Bath Ankylosing Spondylitis Disease Activity Score; CRP, C reactive protein; HLA-B27, human leucocyte antigen; mSASSS, modified Stoke Ankylosing Spondylitis Spine Score; NSAIDs, non-steroidal anti-inflammatory drugs.

Table 2 Baseline demographic, clinical and radiographic characteristics of all patients and the sensitivity analysis group*

\begin{tabular}{lcc}
\hline Assessment & $\begin{array}{c}\text { Patients included in this study } \\
\mathbf{N}=\mathbf{1 8 4} \text { mean (SD) or } \mathbf{n}(\%)\end{array}$ & $\begin{array}{c}\text { Sensitivity analysis group* } \\
\mathbf{N}=\mathbf{8 5} \text { mean (SD) or } \mathbf{n}(\%)\end{array}$ \\
\hline Age (years) & $43(12)$ & $40(10)$ \\
Male gender (\%) & $129(70)$ & $65(76)$ \\
HLA-B27 positive (\%) & $149(83)$ & $70(82)$ \\
Symptoms duration (years) & $20(12)$ & $16(9)$ \\
Disease duration (years) & $11(9)$ & $9(8)$ \\
ASDAS-CRP & $2.6(1.0)$ & $2.7(1.1)$ \\
BASDAI (0-10) & $3.4(2.0)$ & $3.3(2.2)$ \\
CRP (mg/L) & $17.4(23.3)$ & $19.0(24.9)$ \\
Elevated CRP (\%)† & $85(48)$ & $44(54)$ \\
mSASSS (0-72) & $10.8(15.2)$ & $7.8(11.3)$ \\
mSASSS $>0$ (\%) & $140(81)$ & $62(81)$ \\
NSAIDs (\%) & $125(68)$ & $60(71)$ \\
Tumour necrosis factor $\alpha$ inhibitors (\%) & $0(0)$ & $0(0)$ \\
University education (\%) & $14(8)$ & $7(8)$ \\
Monthly personal income $\geq € 1588(\%)$ & $56(35)$ & $34(40)$ \\
Monthly family income $\geq € 3176(\%)$ & $21(19)$ & $13(23)$ \\
Smoker (\%) & $49(39)$ & $35(41)$ \\
Blue-collar worker $(\%)$ & $65(48)$ & $40(47)$ \\
\hline
\end{tabular}

*Sensitivity analysis group: patients included in the study and with the following variables available: occupational activity, smoking status, education and personal income (availability of family income was not demanded because of the higher number of missing values in this variable).

†The cut-off was $10 \mathrm{mg} / \mathrm{L}$ for the Dutch patients and $5 \mathrm{mg} / \mathrm{L}$ for the Belgian and French patients.

ASDAS-CRP, Ankylosing Spondylitis Disease Activity Score (C reactive protein); BASDAl, Bath Ankylosing Spondylitis Disease Activity Score; CRP, C reactive protein; mSASSS, modified Stoke Ankylosing Spondylitis Spine Score; NSAIDs, non-steroidal anti-inflammatory drugs. 
1.82 mSASSS-units/2 years $(95 \%$ CI 1.54 to 2.11$)$ ( $\mathrm{p}=0.05$ for the difference between blue and white-collar workers). When investigating the effect of job type on radiographic progression in subgroups of males and females, statistical significance was lost.

Smoking $(p=0.22)$, education $(p=0.44)$, personal income $(\mathrm{p}=0.99)$ and family income $(\mathrm{p}=0.80)$ were not associated with radiographic progression.

\section{The INDIRECT model: modification of the relationship} between disease activity and radiographic progression by 'job type'

The relationship between ASDAS and radiographic progression was significantly dependent on job type $(\mathrm{p}=0.014)$ : an increase of one ASDAS-unit led to an increase of 1.2 mSASSS-units per 2 years in 'blue-collar' workers but only of $0.2 \mathrm{mSASSS}$ units per 2 years in 'white-collar' workers (table 3). Similar effects were found when the analysis was performed with 'smoking' or 'personal income' instead of 'job types' as explanatory factors, but not with 'educational level' or 'family income'. Note that the effects of 'job type' on this relationship (but also the effects of smoking and personal income) are seen only in men but not in women: an association between ASDAS and radiographic progression in women was almost absent. ${ }^{5}$

In a subsequent analysis, we have tried to disentangle the presumed effects of 'job type' and 'smoking' on the relationship between disease activity and radiographic progression. In the subgroup of smokers, 2-year progression per additional ASDAS-unit in 'blue-collar' workers (1.52 (95\% CI 0.29 to 2.74) mSASSS-units) was slightly higher but not significantly different from that in 'white-collar' workers (1.24 (95\% CI 0.09 to 2.40) mSASSS-units). In the subgroup of non-smokers, 'blue-collar' workers had a 2-year progression of 0.61 (95\% CI 0.18 to 1.05 ) mSASSS progression per additional ASDAS unit increase. Unfortunately, the model did not reach convergence for 'white-collar' workers (35 patients). Further subgroup analyses (in gender and/or personal income strata) were impossible because of the small numbers.

When comparing the fit of the models (with each of the interaction terms included), the model with 'smoking status' had the best fit (QIC 4484), followed by the model with 'job type' (QIC 4565), personal income (QIC 5486) and finally education (QIC 5714). Note that the influence of smoking on the association between ASDAS and radiographic progression was statistically stronger than the effect of 'job type' on this relationship. Sensitivity analysis in patients with all variables available (except for family income due to the higher number of missing values) provided similar results (table 4).

\section{DISCUSSION}

In this study, we have proposed scientific arguments for the hypothesis that long-term physically demanding activities, here operationalised by 'blue-collar job type', amplify the effects of inflammation on bone (syndesmophyte) formation in AS.

We reiterate that the effect of 'job type' on radiographic progression was investigated in two different ways (figure 1): First, we have investigated whether 'job type' was associated with the course of radiographic progression itself (the DIRECT model). In fact, this turned out to be not the case: While progression was initially

Table 3 Effects of disease activity on radiographic progression in subgroups*

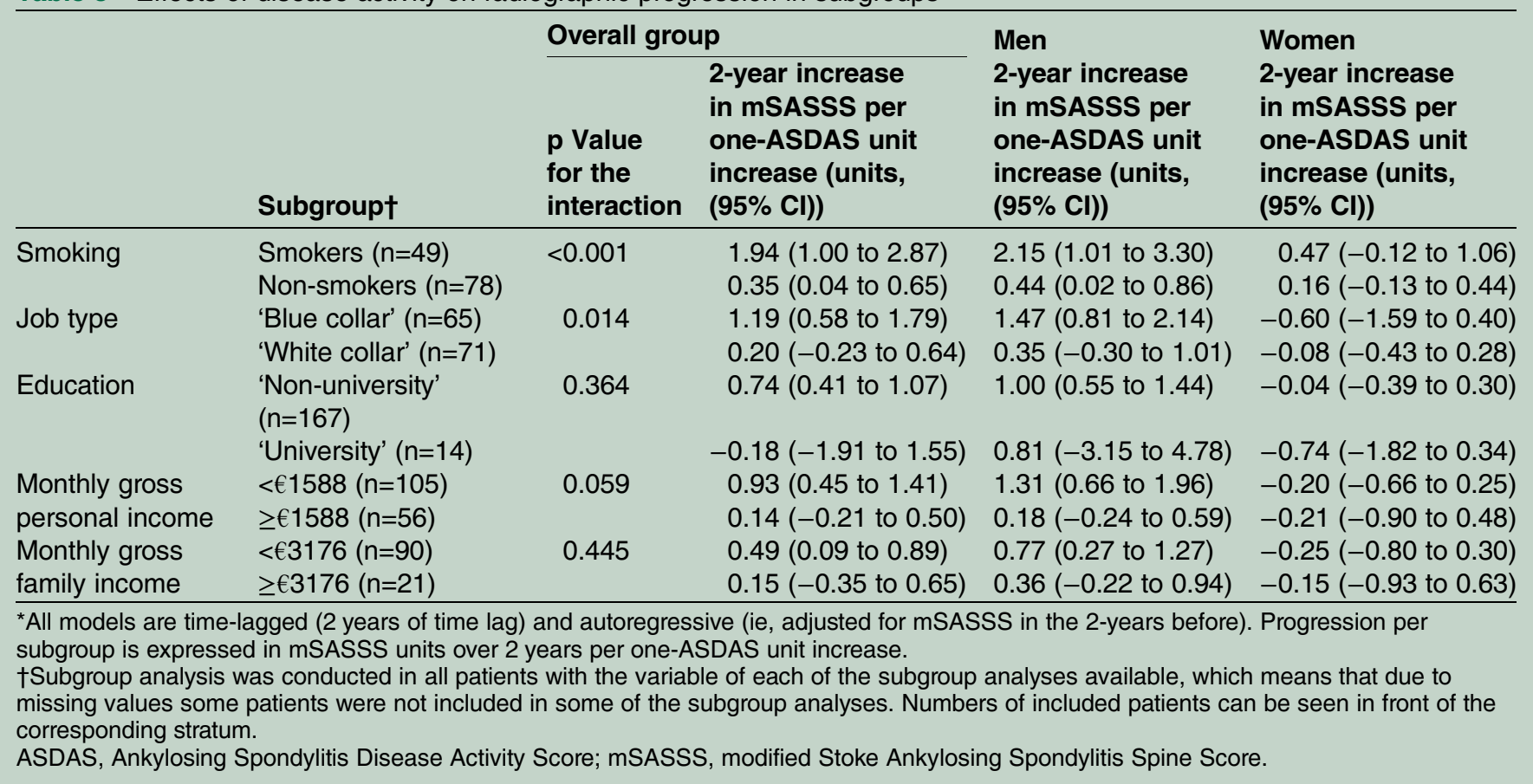


Table 4 Effects of disease activity on radiographic progression in subgroups-sensitivity analysis ${ }^{*}$

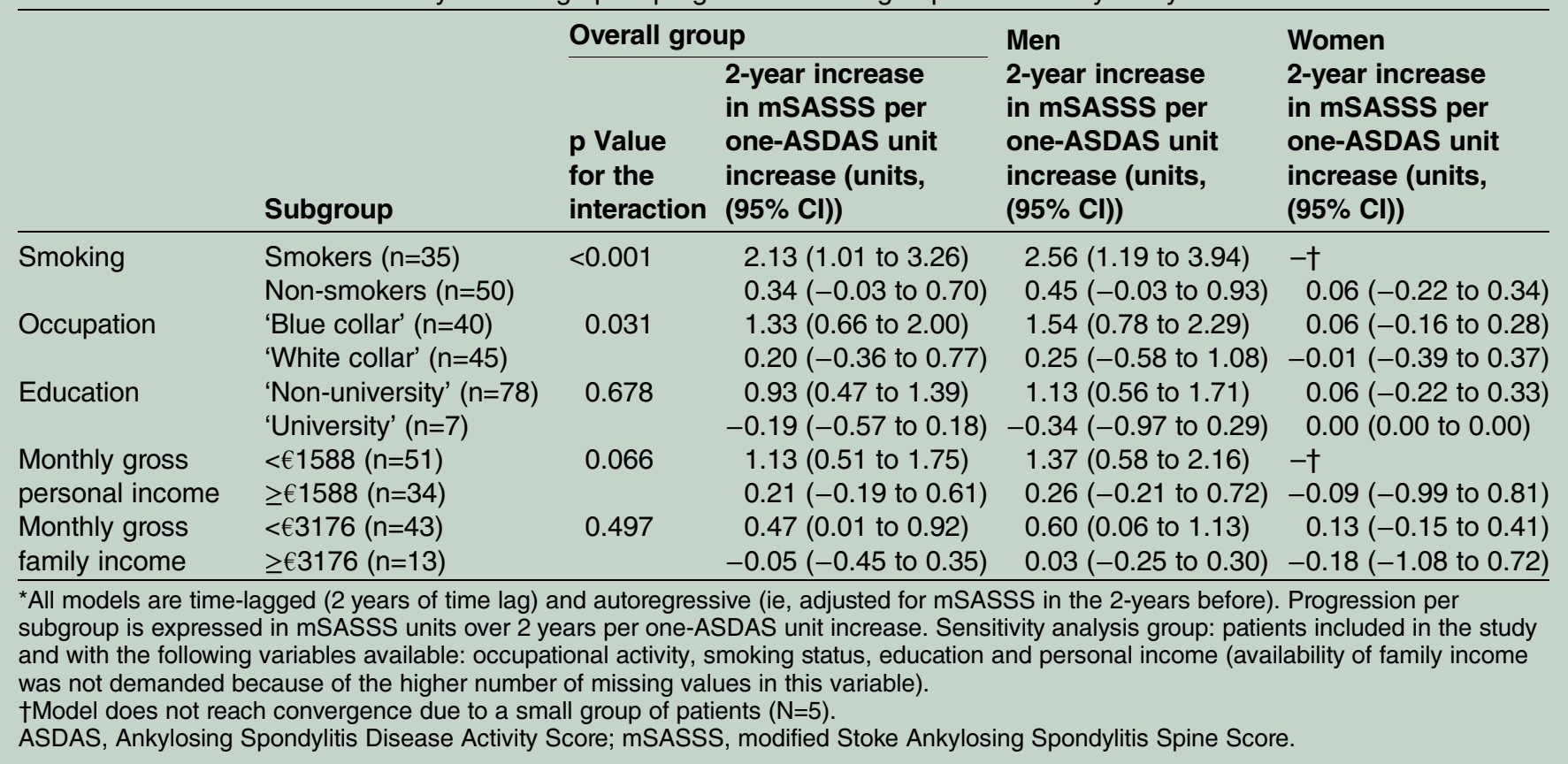

found to be higher in 'blue-collar' than in 'white-collar' workers, this contrast disappeared when repeating the analysis separately in males and females. We have already reported that radiographic progression was higher in men ${ }^{1}$ and 'blue-collar' work is primarily performed by men. The conclusion of this analysis is therefore that strenuous physical activities most likely do not have a strong DIRECT effect on radiographic progression. An intriguing alternative explanation could be that it is physical activity rather than gender that determines radiographic progression in AS, under the assumption that the intensity of physical labour is overall higher in men than in women regardless of 'job type'. However, our study will not give further resolution.

The second type of analyses (the INDIRECT models), however, showed an effect of 'job type' on the reported association of ASDAS and radiographic progression: ${ }^{5}$ 'Blue-collar' work amplified the effect of ASDAS on radiographic progression in comparison with 'whitecollar' work. This means that lifetime strenuous physical activities may increase the detrimental effects of inflammation on radiographic progression. If these findings are confirmed, the implications could be far stretching: the commonly given advice to patients with AS to regularly exercise in order to optimise mobility and quality of life (which is supported by a Cochrane review ${ }^{18}$ and implemented in guidelines ${ }^{19}$ ) may eventually need to be revised, as at least certain types of exercises or mechanical stress on the spine seem to amplify progression of structural damage. If confirmed, this would ultimately imply that (specific types of) physically demanding labour should be discouraged. In what concerns physical exercise in broader terms than professional activity, future research will need to focus on the specific types of physical activity that eventually lead to radiographic progression, to the detriment of others that are more beneficial, especially when taking all the effects of physical activity on health into account. There is some argumentation in the literature to support our findings: The amplifying effects of 'blue-collar' job type on the association between disease activity and radiographic progression can be a consequence of increased strenuous mechanical forces exerted on the spine. This is in concordance with what has recently been shown in animal models, in which mechanical strain has led to new bone formation. ${ }^{7}$

Unfortunately, this study does not provide sufficient explanation for several reasons. First, mechanical strain has also been shown to directly result in inflammation in animal models. ${ }^{7}$ It is plausible that physically demanding jobs in patients with AS may lead to more 'true' inflammation of the spine, and therefore to truly higher ASDAS levels, which in turn may explain more progression. The higher ASDAS levels we found in patients with 'blue-collar' jobs are concordant with such a hypothesis.

Second, we have found similar (or even stronger) interactions with other lifestyle factors such as 'smoking', and also with 'socioeconomic determinants' with regard to the association between ASDAS and radiographic progression. On the other hand, 'job type', 'smoking' and 'socioeconomic status' are strongly related. 'Blue-collar' workers, for example, are more often smokers than 'white-collar' workers, ${ }^{20}$ and 'bluecollar' workers have on average less income than 'whitecollar' workers. The model with 'smoking' had a better data fit (lower QIC) than the model with 'job type'. This raises the question of 'what is the determinant and what is the confounder'? Is it 'job type' that eventually results 
A
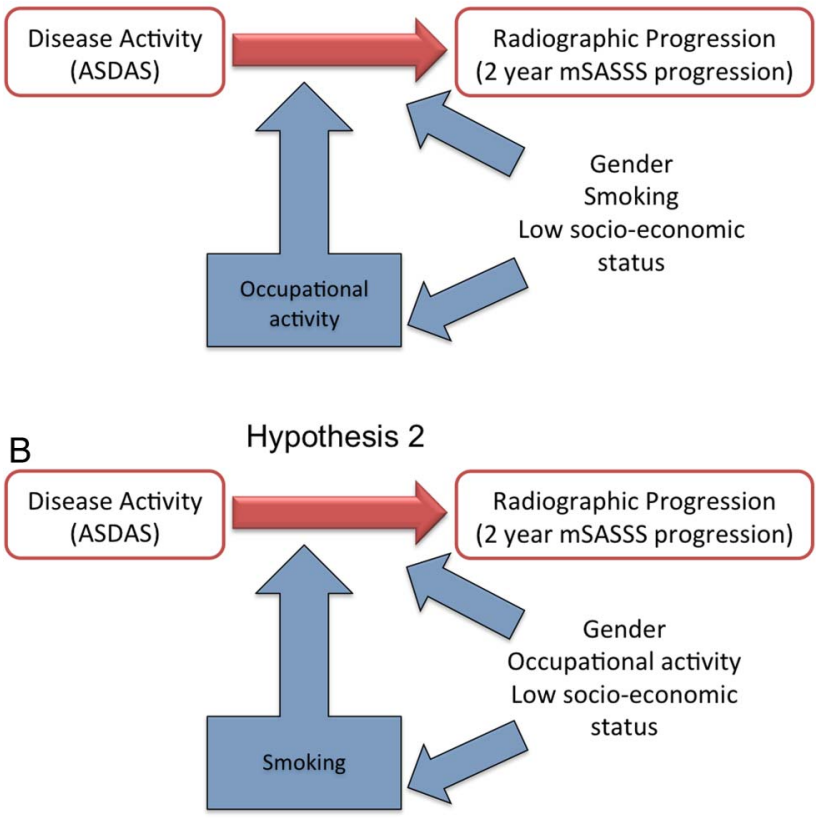

Figure 2 Factors influencing the relationship between disease activity (as measured with the ASDAS) and radiographic progression (as measured with the 2-year mSASSS progression) and possible relationships between them $(A)$ hypothesis 1: occupational activity modifies the relationship between disease activity and radiographic progression and this effect might be confounded by the effect of gender, smoking status and/or low socioeconomic status, which can, for example, be measured with education, personal income, family income. (B) Hypothesis 2: smoking status modifies the relationship between disease activity and radiographic progression and this effect might be confounded by the effect of gender, occupational activity and/or low socioeconomic status. ASDAS, Ankylosing Spondylitis Disease Activity Score; mSASSS, modified Stoke Ankylosing Spondylitis Spine Score.

in more progression, and is 'smoking' an epidemiological confounder; is it 'smoking' that is the primary cause of progression, and is 'job type' the confounder; or do both factors independently convey certain effects (figure 2)? In the appreciation that this study will not give a final verdict, biological plausibility may give some resolution: smoking has been associated in rheumatic diseases with worse outcomes, particularly in rheumatoid arthritis, where it provides an attractive explanation in the debate of citrullinisation of peptides. ${ }^{21}$ While smoking has been associated with several factors of SpA, such as early onset of back pain, more disease activity and more MRI inflammation, ${ }^{22-24}$ and it has also been associated with spinal damage in AS in one study, ${ }^{3}$ an attractive biological explanation is still lacking or at least unproven. ${ }^{3}$ Mechanical stress, on the other hand, has been brought into relation with inappropriate bone formation in several conditions such as $\mathrm{SpA}^{7}$ and osteoarthritis. ${ }^{6}$ It is therefore much more attractive and plausible to suggest that mechanical stress (here somewhat artificially operationalised as 'blue-collar' vs 'white-collar' jobs) is the causative provoking factor, and 'smoking'-known to be associated with 'blue-collar' work - the confounder, rather than vice versa. An explanation that cannot be excluded is that both 'job type' and 'smoking' are independently contributory. In this discussion, we propose that 'personal income' and, to a lesser extent, 'education' and 'family income', while being proven modifiers of the relationship between ASDAS and radiographic progression, do not have biological plausibility and should be considered as confounders, id est: 'personal income' and others are subordinate to 'job type'. In analogy with many rheumatic diseases, the association of socioeconomic variables with outcome of disease also is intriguingly present here. ${ }^{25-28}$

As far as we know, the role of occupational activities, smoking or socioeconomic factors on the course of radiographic progression over the long term has not been investigated previously and we cannot compare our findings with others.

This study has several additional limitations worth mentioning. The sample size of this observational study is not large enough to allow subtle but complex relationships in critically relevant subgroups (eg, smokers vs non-smokers and men vs women). On the other hand, larger cohorts without biological treatment but a more meticulous follow-up than this one will most likely never be conducted.

An important limitation is that we assumed the dichotomy of 'blue-collar' versus 'white-collar' jobs as being representative of a high versus low level of mechanical stress on the spine. We cannot exclude the possibility that 'white-collar' workers follow more thoroughly the physicians' recommendations to intensively exercise and thus compensate lower levels of physical activity during working hours with higher levels of exercise. However, regardless of what epidemiological mechanism may have worked against the effects of 'job type', the effects are significant and relevant.

Another limitation of this study is that we have modelled 'job type' at baseline as being representative of 'job type' during follow-up. However, from the patients with data on job type over time available, only one patient changed his job type, which confirms that people tend to practise the same type of profession over several years. Moreover, since OASIS is not an inception cohort but symptom duration was on average 20 years at the start, it is most likely that changes due to the onset of back pain are made before the inclusion in the cohort.

What impact do the findings in this study and the previous one ${ }^{5}$ have with regard to explaining syndesmophyte formation in AS? We have previously identified important determinants of syndesmophyte formation in patients with AS: it occurs primarily in HLA-B27-positive male patients, reiterating the constitutive (genetic) component. ${ }^{1}$ Disease activity (inflammation) does have an influence on the rate of progression, but primarily in (genetically) susceptible (male) patients. ${ }^{5}$ In addition, we have now made likely that-among other factors still 
to be identified-lifetime physical activities during working hours may amplify the detrimental effects of inflammation on radiographic progression. Whether smoking is an independent modifier of this relationship or only a confounder still needs to be elucidated.

\section{Author affiliations}

${ }^{1}$ Department of Clinical Immunology \& Rheumatology, Amsterdam Rheumatology Center, University of Amsterdam, Amsterdam, The Netherlands ${ }^{2}$ Department of Rheumatology, Hospital Garcia de Orta, Almada, Portugal ${ }^{3}$ Department of Rheumatology, Atrium Medical Center, Heerlen,

The Netherlands

${ }^{4}$ Department of Medicine, Division of Rheumatology, Maastricht University Medical Center, Maastricht, The Netherlands

${ }^{5}$ School for Public Health and Primary Care (CAPHRI), University of Maastricht, Maastricht, The Netherlands

${ }^{6}$ Department of Rheumatology, Hôpital Cochin, Paris-Descartes University, Paris, France

${ }^{7}$ Clinical Epidemiology and Biostatistics, PRES Sorbonne Paris-Cité, Paris, France

${ }^{8}$ Department of Rheumatology, University of Ghent, Ghent, Belgium ${ }^{9}$ Department of Rheumatology, Leiden University Medical Center, Leiden, The Netherlands

Contributors SR, RL, AvT, AB and DvdH designed the study. SR, RL, AvT, $A B, C S, F v d B, M D$ and DvdH collected the data. SR and CS read the radiographs. AvT was the adjudicator. $S R, R L, A v T, A B$ and $D v d H$ analysed the data and critically interpreted the results. SR prepared the first version of the manuscript. All authors reviewed the draft versions and gave their approval of the final version of the manuscript.

Funding SR was supported by the Fundação para a Ciência e Tecnologia (FCT) grant SFRH/BD/68684/2010

Competing interests None declared.

Patient consent Obtained

Ethics approval The ethics committee from all participating hospitals approved the study (Paris, Maastricht, Ghent).

Provenance and peer review Not commissioned; externally peer reviewed.

Open Access This is an Open Access article distributed in accordance with the Creative Commons Attribution Non Commercial (CC BY-NC 4.0) license, which permits others to distribute, remix, adapt, build upon this work noncommercially, and license their derivative works on different terms, provided the original work is properly cited and the use is non-commercial. See: http:// creativecommons.org/licenses/by-nc/4.0/

\section{REFERENCES}

1. Ramiro S, Stolwijk C, van Tubergen A, et al. Evolution of radiographic damage in ankylosing spondylitis: a 12 year prospective follow-up of the OASIS study. Ann Rheum Dis 2013;74:52-9.

2. Baraliakos X, Listing J, Rudwaleit M, et al. Progression of radiographic damage in patients with ankylosing spondylitis: defining the central role of syndesmophytes. Ann Rheum Dis 2007:66:910-15.

3. Poddubnyy $\mathrm{D}$, Haibel $\mathrm{H}$, Listing $\mathrm{J}$, et al. Baseline radiographic damage, elevated acute-phase reactant levels, and cigarette smoking status predict spinal radiographic progression in early axial spondylarthritis. Arthritis Rheum 2012;64:1388-98.

4. van Tubergen A, Ramiro S, van der Heijde D, et al. Development of new syndesmophytes and bridges in ankylosing spondylitis and their predictors: a longitudinal study. Ann Rheum Dis 2012;71:518-23.

5. Ramiro S, van der Heijde D, van Tubergen A, et al. Higher disease activity leads to more structural damage in the spine in ankylosing spondylitis: 12-year longitudinal data from the OASIS cohort. Ann Rheum Dis 2014;73:1455-61.
6. van der Kraan PM, van den Berg WB. Osteophytes: relevance and biology. Osteoarthritis Cartilage 2007;15:237-44.

7. Jacques $\mathrm{P}$, Lambrecht $\mathrm{S}$, Verheugen $\mathrm{E}$, et al. Proof of concept: enthesitis and new bone formation in spondyloarthritis are driven by mechanical strain and stromal cells. Ann Rheum Dis 2014;73:437-45.

8. Ward MM, Reveille JD, Learch TJ, et al. Occupational physical activities and long-term functional and radiographic outcomes in patients with ankylosing spondylitis. Arthritis Rheum 2008;59:822-32.

9. Tehranifar P, Liao Y, Ferris JS, et al. Life course socioeconomic conditions, passive tobacco exposures and cigarette smoking in a multiethnic birth cohort of U.S. women. Cancer Causes Control 2009;20:867-76.

10. Franks $P$, Jerant AF, Leigh JP, et al. Cigarette prices, smoking, and the poor: implications of recent trends. Am J Public Health 2007;97:1873-7.

11. Sherriff NS, Coleman L. Understanding the needs of smokers who work as routine and manual workers on building sites: results from a qualitative study on workplace smoking cessation. Public Health 2013;127:125-33.

12. Spoorenberg A, van der Heijde D, de Klerk E, et al. Relative value of erythrocyte sedimentation rate and C-reactive protein in assessment of disease activity in ankylosing spondylitis. J Rheumatol 1999;26:980-4

13. Creemers MC, Franssen MJ, van't Hof MA, et al. Assessment of outcome in ankylosing spondylitis: an extended radiographic scoring system. Ann Rheum Dis 2005;64:127-9.

14. Wanders A, Landewe R, Spoorenberg A, et al. Scoring of radiographic progression in randomised clinical trials in ankylosing spondylitis: a preference for paired reading order. Ann Rheum Dis 2004;63:1601-4.

15. van der Heijde D, Lie E, Kvien TK, et al. ASDAS, a highly discriminatory ASAS-endorsed disease activity score in patients with ankylosing spondylitis. Ann Rheum Dis 2009;68:1811-18.

16. Schreuder KJ, Roelen CA, Koopmans PC, et al. Job demands and health complaints in white and blue collar workers. Work 2008;31:425-32.

17. Gaudette LA, Richardson A, Huang S. Which workers smoke? Health Rep 1998;10:35-45 (ENG); 35-47 (FRE).

18. Dagfinrud H, Kvien TK, Hagen KB. Physiotherapy interventions for ankylosing spondylitis. Cochrane Database Syst Rev 2008;(1): CD002822.

19. Braun J, van den Berg R, Baraliakos $X$, et al. 2010 update of the ASAS/EULAR recommendations for the management of ankylosing spondylitis. Ann Rheum Dis 2011;70:896-904.

20. Kotz $D$, West $R$. Explaining the social gradient in smoking cessation: it's not in the trying, but in the succeeding. Tob Control 2009;18:43-6.

21. Klareskog L, Malmstrom V, Lundberg $\mathrm{K}$, et al. Smoking, citrullination and genetic variability in the immunopathogenesis of rheumatoid arthritis. Semin Immunol 2011;23:92-8.

22. Chung HY, Machado P, van der Heijde D, et al. Smokers in early axial spondyloarthritis have earlier disease onset, more disease activity, inflammation and damage, and poorer function and health-related quality of life: results from the DESIR cohort. Ann Rheum Dis 2012;71:809-16.

23. Ward MM, Hendrey MR, Malley JD, et al. Clinical and immunogenetic prognostic factors for radiographic severity in ankylosing spondylitis. Arthritis Rheum 2009;61:859-66.

24. Kaan U, Ferda $\mathrm{O}$. Evaluation of clinical activity and functional impairment in smokers with ankylosing spondylitis. Rheumatol Int 2005;25:357-60.

25. Mackenbach JP, Stirbu I, Roskam AJ, et al. Socioeconomic inequalities in health in 22 European countries. $N$ Engl $J$ Med 2008;358:2468-81.

26. Callahan LF, Cleveland RJ, Shreffler J, et al. Associations of educational attainment, occupation and community poverty with knee osteoarthritis in the Johnston County (North Carolina) osteoarthritis project. Arthritis Res Ther 2011;13:R169.

27. Mackie SL, Taylor JC, Twigg S, et al. Relationship between area-level socio-economic deprivation and autoantibody status in patients with rheumatoid arthritis: multicentre cross-sectional study. Ann Rheum Dis 2012;71:1640-5.

28. Brennan SL, Turrell G. Neighborhood disadvantage, individual-level socioeconomic position, and self-reported chronic arthritis: a crosssectional multilevel study. Arthritis Care Res (Hoboken) 2012;64:721-8. 